\title{
Fracture analysis of fisheye failures in the tooth root fillet of high-strength gears made out of ultra-clean gear steels
}

\author{
D. Fuchs ${ }^{1}(\mathbb{D}) \cdot$ S. Rommel ${ }^{1}$ (D) $\cdot$ T. Tobie $^{1}(\mathbb{D}) \cdot$ K. Stahl $^{1} \mathbb{1}$ \\ Received: 16 June 2021 / Accepted: 12 October 2021 / Published online: 4 November 2021 \\ (c) The Author(s) 2021
}

\begin{abstract}
In shot-peened components, failures can be caused by a crack initiation below the surface at a non-metallic inclusion in the steel matrix. This fracture mechanism is called "fisheye failure". In addition, this failure type can lead to a decreased endurance fatigue limit for the component. By preventing this crack mechanism, higher bending strength is expected to be achievable. Various research by universities and research institutes has taken place in this field using standard specimen and sometimes special alloy systems. However, in the tooth root of a gear, a complex multiaxial stress condition is present. Furthermore, the most commonly gears used in transmissions are made out of case-hardened wrought steels. Therefore, in the gear industry, there is only limited knowledge available about this failure type and the failure characteristics, so far. The first step to gain more knowledge requires extended and proper characterization of the crack area. Furthermore, in standardized gear calculation methods a consideration of a crack initiation below the surface at non-metallic inclusions is not possible, yet. Therefore, extended model approaches are still necessary. However, the reliability of such model approaches depends strongly on the quality of the input data, which can only be ensured by a proper fracture surface analysis. As a starting point, the aim of this paper is to characterize systematically the fracture area characteristics in the tooth root fillet of case-hardened, shot-peened gears in detail according to a presented approach to further extend a presented extended model approach in the medium term.
\end{abstract}

D. Fuchs

fuchs@fzg.mw.tum.de

$1 \quad$ FZG-Gear Research Center, Technical University of

Munich, Boltzmannstraße 15, 85748 Garching, Germany 


\section{Bruchflächenanalyse von Zahnfußbrüchen von unterhalb der Oberfläche an nicht-metallischen Einschlüssen bei hochtragfähigen Zahnrädern aus hochreinen Zahnradstählen}

\section{Zusammenfassung}

Bei kugelgestrahlten Bauteilen kann eine Rissinitiierung unterhalb der Oberfläche an einem nicht-metallischen Einschluss in der Stahlmatrix stattfinden. Dieser Ausfallmechanismus wird im Deutschen als Bruchlinsenversagen und im Englischen als "fisheye failure" bezeichnet. Darüber hinaus kann dieser Ausfallmechanismus zu einer verminderten Dauerfestigkeit des Bauteils führen. Es wird erwartet, dass durch die Hemmung dieses Rissmechanismus eine höhere Dauerfestigkeit erreicht werden kann. Auf diesem Forschungsgebiet wurden bereits verschiedene Untersuchungen an Universitäten und Forschungsinstituten durchgeführt, wobei im Rahmen der Untersuchungen einfache Standardproben und zuweilen spezielle Legierungssysteme verwendet wurden. Im Zahnfuß eines Zahnrads liegt jedoch ein komplexer, multiaxialer Spannungszustand vor und die meisten Zahnräder in Getrieben werden aus einsatzgehärteten Zahnradstählen hergestellt. Daher gibt es in der Getriebeindustrie bisher nur begrenzte Kenntnisse über das Bruchlinsenversagen und dessen Versagenscharakteristik. Eine erste Maßnahme zur Generierung weiteren Wissens erfordert eine vollumfängliche und angepasste Charakterisierung des Rissausgangsortes. Darüber hinaus ist in standardisierten Zahnradberechnungsverfahren eine Berücksichtigung einer Rissinitiierung von unterhalb der Oberfläche an nicht-metallischen Einschlüssen bisher nicht möglich. Daher sind weiterhin höherwertige Modellansätze notwendig. Die Zuverlässigkeit solcher höherwertigeren Modellansätze hängt jedoch stark von der Qualität der Eingangsdaten ab, die nur durch eine geeignete Bruchflächenanalyse sichergestellt werden kann. Ziel dieser Arbeit ist es, die Bruchflächencharakteristik im Zahnfuß einsatzgehärteter, kugelgestrahlter Zahnräder nach einer vorgestellten Vorgehensweise systematisch und detailliert zu charakterisieren, um mittelfristig den vorgestellten, höherwertigen Modellansatz weiterzuentwickeln.

$\begin{array}{ll}\text { Abbreviations } \\ \text { NMI } & \text { Non-metallic inclusion } \\ \text { ODA } & \text { Optically dark area } \\ \text { FVA } & \begin{array}{l}\text { German Drive Technology Research Association } \\ \text { (registered association) }\end{array} \\ \text { SEP } & \text { Steel test specification } \\ \text { Eq } & \text { Equation } \\ \text { EDX } & \text { Energy-dispersive X-ray } \\ \text { c.f. } & \text { Abbreviation for compare }\end{array}$

\section{Introduction}

Nowadays, gearboxes must meet steadily increasing as well as completely new requirements, be it due to the trend towards green energy or to the electrification of the powertrain. In the wind power industry, long operating durations are required. In powertrains for e-mobility applications, high-speed approaches are being investigated and fewer

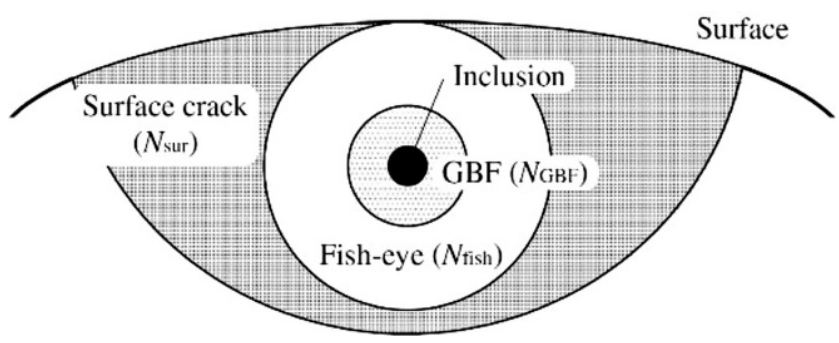

Fig. 1 Schematic illustration of fisheye failure acc. to [3] gear stages are needed. In both examples, the number of load cycles for the gears is much higher than in the past. Therefore, a higher gear load carrying capacity in relation to endurance fatigue is needed.

A shot-peening process can strengthen the tooth root fillet of a gear and will most likely raise the tooth root bending strength. However, research shows that for shot-peened tooth root fillets, there can be a change in the crack mechanism. Due to the induced compressive residual stresses, a so-called fisheye failure can initiate at a non-metallic inclusion below the surface. Various research was performed to investigate fisheye failures at research institutes using standard specimen (tension-compression and rotating bending specimen) and sometimes special alloy systems. However, in the tooth root of a gear, a complex multiaxial
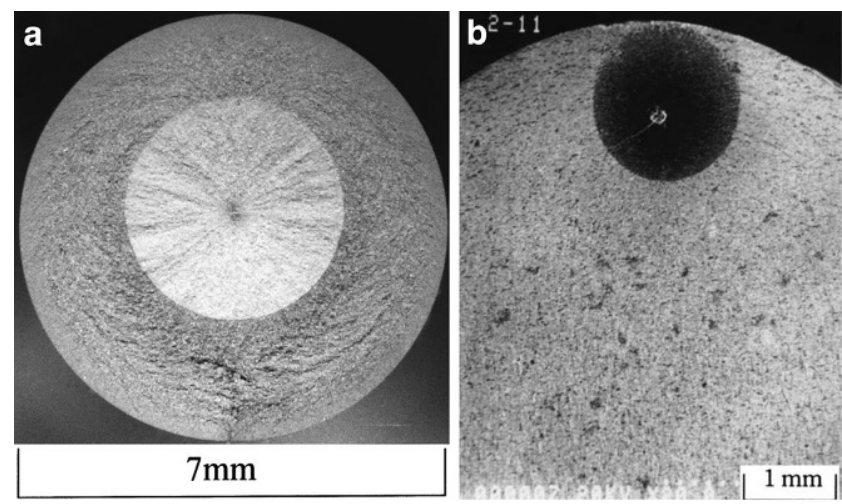

Fig. 2 Different fisheye shapes and positions. a Tension-compression specimen [7]. b Rotating bending specimen [6] 


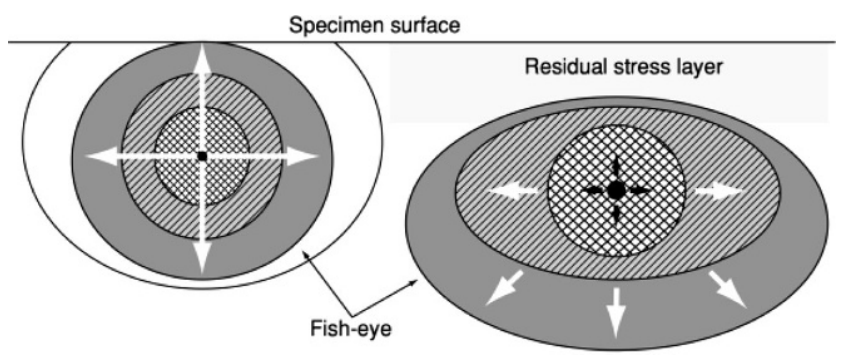

Fig. 3 Fisheye form (left) in a heat-treated and unpeened specimen; and (right) in a heat-treated and shot-peened specimen [8]

Table 1 Inclusion types and morphologies according to ISO 4967 [9]

\begin{tabular}{ll}
\hline Group $A$ & Sulfide type \\
Group B & Aluminate type \\
Group $C$ & Silicate type \\
Group $D$ & Globular oxide type \\
Group $D S$ & Single globular type \\
\hline
\end{tabular}

stress condition is present. Furthermore, the most commonly gears used in transmissions are made out of casehardened wrought steels. Therefore, in the world of gears, there is only limited knowledge available in this field about this failure type and the failure characteristics, so far. A first step to gain more knowledge requires extended and proper characterization of the fracture area.

Furthermore, in standardized gear calculation methods, like AGMA 2001-D04 [1] or ISO 6336 [2], a consideration of a crack initiation from below the surface at non-metallic inclusion (fisheye fracture) is not possible, yet. Therefore, extended model approaches are still necessary. However, the reliability of such model approaches depends strongly on the quality of the input data, which can only be ensured with a proper fracture surface analysis. As a starting

Fig. 4 Typical morphologies of non-metallic inclusions in steel. a elongated. b spherical. c stringer

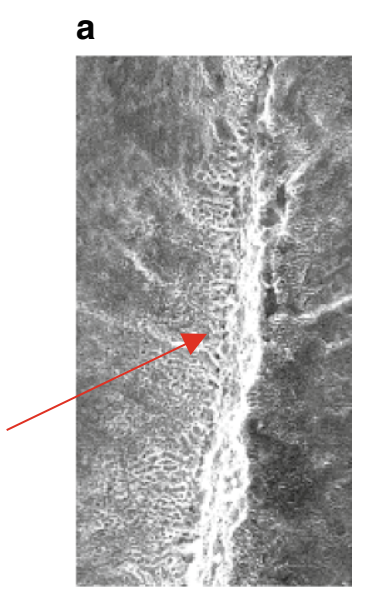

point, the aim of this paper is to characterize systematically the crack area characteristics in the tooth root fillet of case-hardened, shot-peened gears in detail according to a presented approach to further extend a presented model approach in the medium term.

\section{Overview of the state of knowledge}

A fisheye failure is characterized by an optically brighter area in the fractured surface; see Fig. 1. Typically, in the center is a non-metallic inclusion, which is responsible for the crack initiation. Usually, a darker-appearing area is visible around the non-metallic inclusion. In Fig. 1 the darker area is named "GBF" acc. to the nomenclature of Shiozawa et al. [3]. When the fisheye expansion reaches a certain area, the crack will propagate through the rest of the material.

In the past, extensive experimental investigations with tension-compression or rotating bending fatigue specimens have been conducted on this type of crack mechanism, for example in [4-6]. In the course of the aforementioned research projects, the fisheye was usually characterized by its area and the non-metallic inclusion was characterized by its size and resulting area and chemical composition. In the following, the common characteristics of fisheye failures will be presented.

\subsection{Characteristics of fisheye failures}

Within the literature, generally, two geometrical shapes and positions for fisheyes are shown. In tension-compression specimens the shape of the fisheye is circular, and it is located in the center of the specimen (see Fig. 2a). In rotating bending specimens, the form of the fisheye is usually
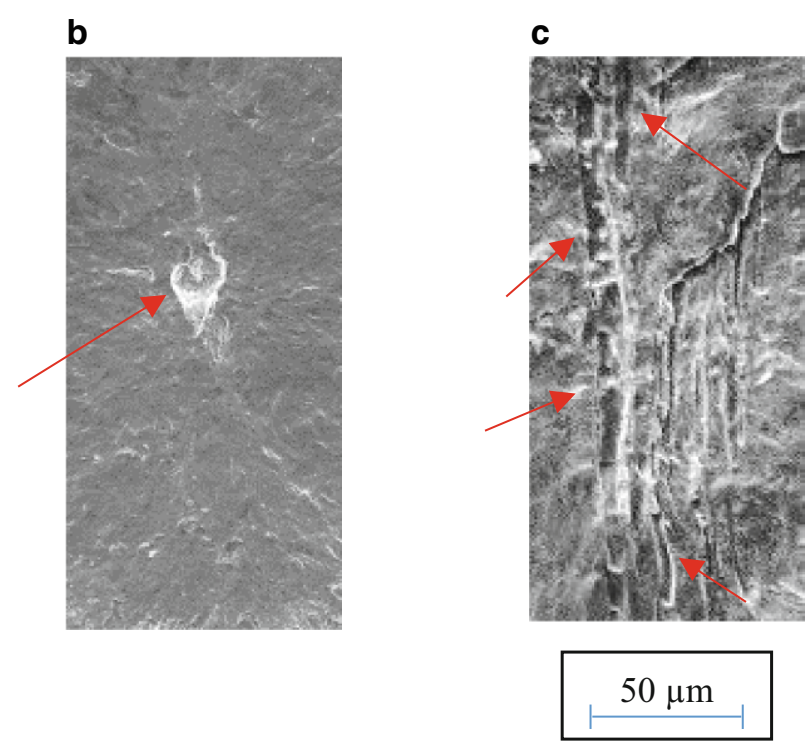


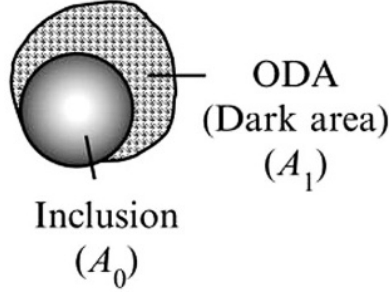

Fig. 5 Globular inclusion and dark area "ODA" [10]

slightly oval and is located at the edge of the specimen (see Fig. 2b).

In [8], heat-treated and unpeened gear specimens displayed a circular fisheye, whereas heat-treated and shotpeened specimens had an ellipsoidal form, c.f. Fig. 3. The difference can be attributed to the different stress conditions during the tests and the material properties in the center and at the edge of the specimen. There is no proper documen- tation in the literature on how the area of the fisheye is to be determined exactly. It is assumed that the area of the fisheye is derived from its circumference.

Non-metallic inclusions and their morphology are classified into five groups according to ISO 4967 [9]; see Table 1. In typical gear steels, like $\mathrm{MnCr}$ or CrNiMo-alloyed steels, the most common inclusion types found are aluminum oxides $\left(\mathrm{Al}_{2} \mathrm{O}_{3}\right)$, manganese sulfides $(\mathrm{MnS})$, and titanium nitrides (TiN). Furthermore, mixed inclusions and minor elements, like calcium $(\mathrm{Ca})$, can be found. The morphology of non-metallic inclusions can be elongated, spherical, or the shape of stringers; c.f. Fig. 4.

Non-metallic inclusions are spatial defects in a steel matrix. However, when stressed in the direction of the maximum tensile stress, the non-metallic inclusion can be seen as a two-dimensional void according to the model approach of Murakami [6]. According to Murakami the non-metallic a

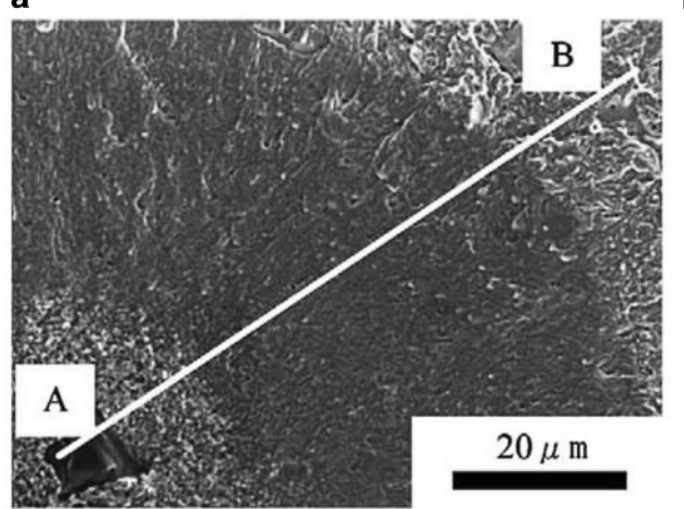

b

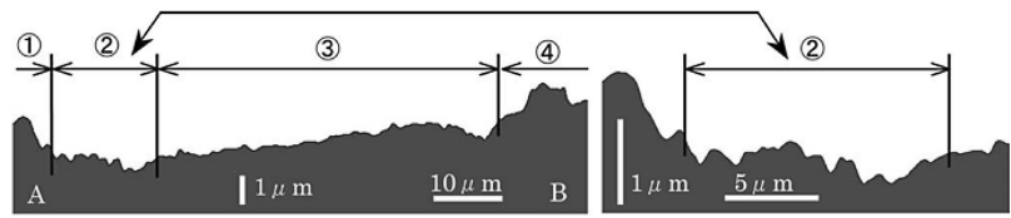

Fig. 6 a SEM observation of a fisheye type fracture surface; b Surface roughness plot along a cutting plane line (A to B) at a fisheye [14] (key: (1) Inclusion (2) GBF zone (3) Fisheye (4) Outside the fisheye)

Fig. 7 Schematic diagram of a model approach for the evaluation of the tooth root bending strength of gears [21]

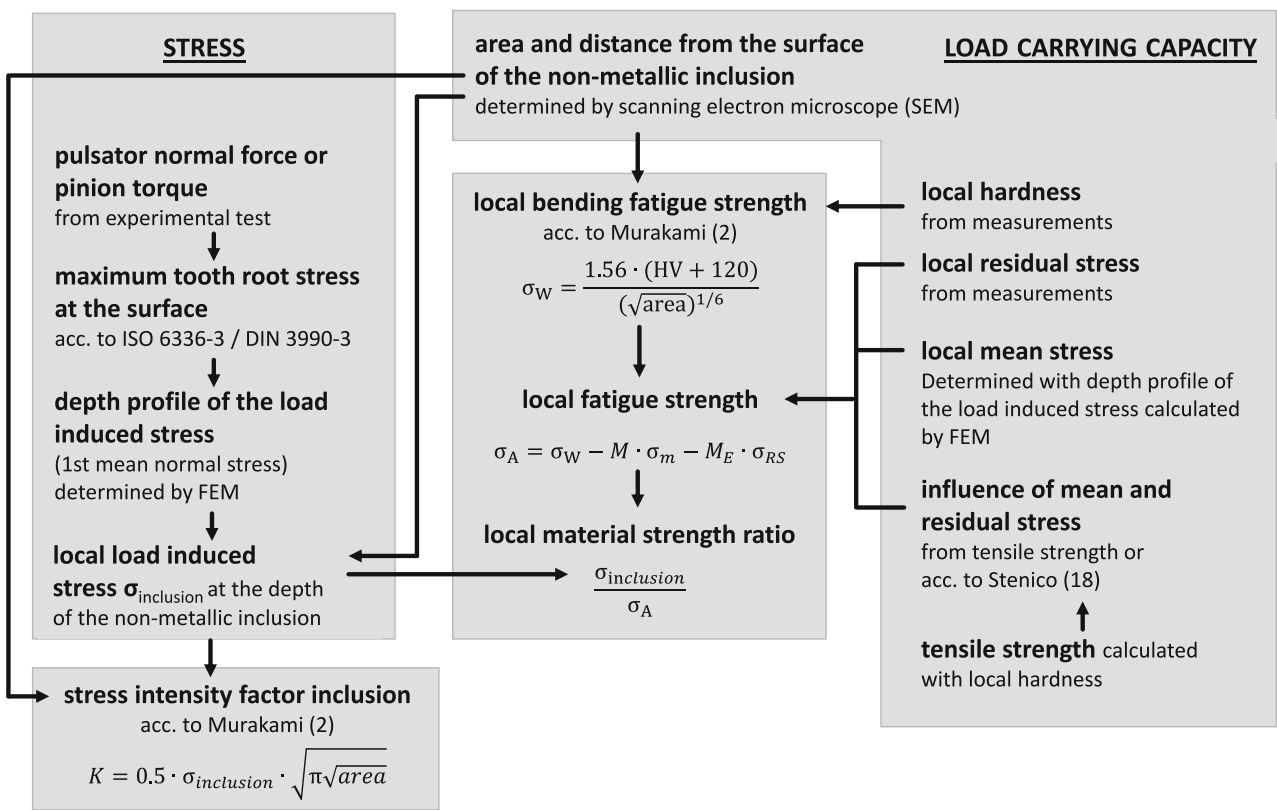


Fig. 8 Test rigs used for investigations on the tooth root bending strength. a FZG backto-back test rig (center distance $\mathrm{a}=91.5 \mathrm{~mm})$ [28]. b Pulsator test rig [29]

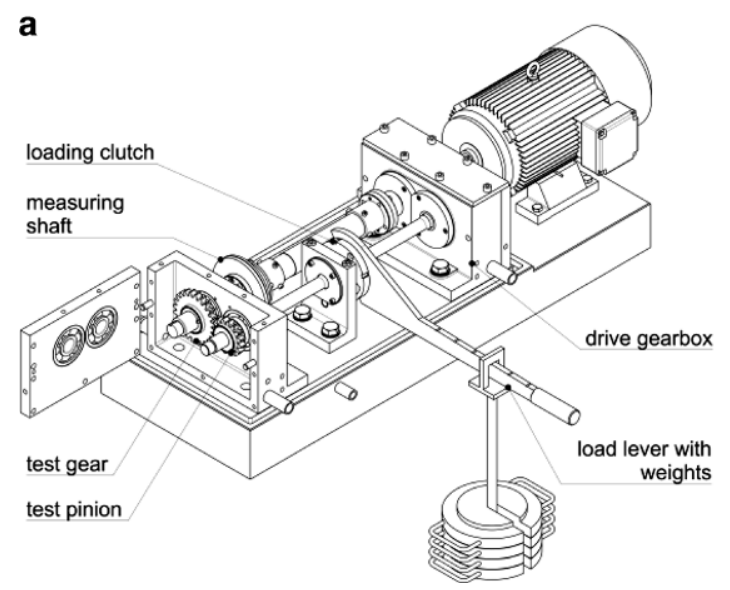

inclusion can be seen as an actual void. No stress step-up is assumed due to the non-metallic inclusion, even when the non-metallic inclusion de-bonds from the steel matrix. According to Murakami [6], the area of a non-metallic inclusion can be determined approximately as a circular area. This approach applies very well to globular oxide inclusions. However, aluminum oxides and manganese sulfides in gear steels can also be found as elongated or stringer inclusions; c.f. Fig. 4. In these cases, this approximation does not fit.

There is no proper documentation in the literature on how the area of the inclusion is to be determined exactly. It is assumed that either the area is derived from the circumference or an approximation using a basic geometric shape is made.

Often, a darker-appearing area around the non-metallic inclusion can be detected $[10,11]$; c.f. Fig. 5 . The theory is that the formation of the dark area starts at the non-metallic inclusion. It then grows non-uniformly until it reaches a certain threshold, where the rest of the fisheye starts to form.

There are several theories on how the dark area is formed and therefore different nomenclatures:

Table 2 Overview of the investigated variants and their characteristics

\begin{tabular}{llll}
\hline Variant & Alloy system & $\begin{array}{l}\text { Diameter of } \\
\text { steel bar in } \mathrm{mm}\end{array}$ & $\begin{array}{l}\text { Area reduction } \\
\text { ratio }\end{array}$ \\
\hline OW1 & EN20MnCr5 & 125 & $8: 1$ \\
S4 & & 105 & $8: 1$ \\
S6 & & 105 & $8: 1$ \\
S8 & & 100 & $8: 1$ \\
OW4 & & 100 & $8: 1$ \\
OW3 & EN18CrNiMo7-6 140 & $8: 1$ \\
OW5 & & 140 & $27: 1$ \\
OW7 & EN20NiMo9-7 & 130 & $12: 1$ \\
S9 & EN18NiCr5-4 & 110 & $17: 1$ \\
\hline
\end{tabular}

- ODA: Optically dark area acc. to Murakami [10, 11]

- GBF: Granular-bright facet acc. to Shiozawa et al. [3]

- FGA: Fine granular area acc. to Sakai [5, 12]

- RSA: Rough surface area acc. to Ochi et al. [13]

In the course of this publication, the nomenclature "ODA" acc. to Murakami is used. Shiozawa et al. present at a fisheye fracture a surface roughness plot along a cutting plane line $[3,14]$. It can be seen that the granular-bright facet (GBF) zone has a different roughness to the rest of the fisheye. The ODA and its properties are also discussed in [15-18]. (Fig. 6).

There is no proper documentation in the literature on how the area of the dark area is to be determined exactly. Murakami [11] summarizes the area of the NMI and the dark area to determine the area of the ODA; see Eq. 1. It is assumed that the area of the dark area $A_{1}$ is derived from the circumference.

$\sqrt{A_{\mathrm{ODA}}}=\sqrt{A_{0}+A_{1}}$

\subsection{Model approach for considering the influence of non-metallic inclusions on the tooth root load carrying capacity of gears}

In standardized gear calculation methods a consideration of a crack initiation from below the surface at non-metallic inclusions is not possible, yet, and extended model approaches are still necessary. The area of the non-metallic inclusion is usually one of the main parameters for local calculation approaches for predicting the tooth root bending strength. However, the reliability of such an extended model approach is very much dependent on the quality of the input data.

An extended model approach for the evaluation of the tooth root bending strength of gears, which is based on the model approach of Murakami [19, 20], was presented in 


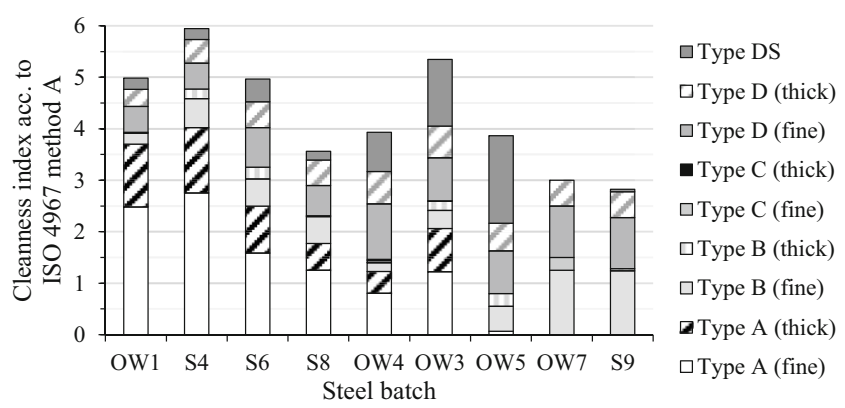

Fig. 9 Stacked bar diagram of the degree of cleanliness according to ISO 4967 Method A [9] of the steel batches investigated

[21]. This model approach allows a consideration of the effects of non-metallic inclusions in the matrix of gear steels on the tooth root bending strength. Fig. 7 illustrates this model approach for gears. As main input data, the characteristics of the non-metallic inclusions are used, like the area and the distance from the surface of the non-metallic inclusion. However, the influence of the ODA, for example, is not yet taken into account.

\subsection{Summary}

Various aspects have to be taken in account when characterizing fisheye failures. For example, the size respectively area of the fisheye, the form and chemical composition of the non-metallic inclusions and the characteristics of the ODA. However, no extensive studies on fisheye failure characteristics in the tooth root fillet of case-hardened, shotpeened gears can be found in the literature so far.

Extended model approaches are still necessary, to consider the influence of non-metallic inclusions on the tooth root bending strength of shot-peened gears. However, the reliability of such extended model approaches is strongly dependent on the data quality. However, in the literature different and sometimes not fully documented assumptions and approaches have been used so far to document fisheye characteristics. It can be summarized that still a deeper understanding of the characteristics of fisheye fractures in shot-peened gears is necessary and the input data quality for model approaches has to be ensured to get reliable results.

\section{Aim of the investigation}

Extensive experimental investigations on case-hardened, shot-peened gears in the high cycle fatigue range, which had failed mostly due to fisheye failures, have been conducted by Schurer [22], Bretl [23] and Stenico [24] in the past. The tests were done with FZG back-to-back as well as pulsator test rigs. The test rigs are shown in Fig. 8. The experimental investigations were done up to 15,30 respectively 50 million load cycles and it was shown that even up to a higher number of load cycles the load carrying capacity still decreases. Some of the experimental results have already been internationally published in [25] and [26]. First investigations into crack area characteristics of these fisheye fractures were also already presented in [27]. The investigations in [27] show, for example, that in the fisheye fracture surface of gears also an ODA is present.

In the course of FVA research project 293 IV [30], which builds on the results and conclusions of [22-24] and especially on [27], extensive experimental investigations with the focus on the very high cycle fatigue range of gears made out of ultra-clean gear steels were performed. Ultra-clean gear steels were used to examine, if by using such gear steels a crack initiation below the surface at non-metallic inclusions can be prevented and higher load carrying capacities are possible. Gear sizes with a normal module of $\mathrm{m}_{\mathrm{n}}=1.5$ and $5 \mathrm{~mm}$ were used for the investigations on the FZG back-to-back test rig and on the Pulsator test rig.

The alloy systems of these ultra-clean gear steels were $\mathrm{MnCr}, \mathrm{CrNiMo}, \mathrm{NiCr}$ and NiMo. Table 2 presents an overview of the steel batches, alloy systems, diameters of the steel bars and area reduction ratios. All area reduction ratios are above the specification value of $5: 1$ for continuous casting according to ISO 6336-5 [31].

Table 3 Chemical analysis of ultra-clean steel batches

\begin{tabular}{llllllllllll}
\hline Variant & Alloy system & \multicolumn{9}{l}{ Chemical composition in mass-\% } & \multicolumn{1}{l}{} \\
\cline { 3 - 11 } & & $\mathrm{C}$ & $\mathrm{Mn}$ & $\mathrm{Cr}$ & $\mathrm{Ni}$ & $\mathrm{Mo}$ & $\mathrm{S}$ & $\mathrm{Al}$ & $\mathrm{Cu}$ & $P$ \\
\hline OW1 & EN20MnCr5 & 0.20 & 1.17 & 1.15 & 0.12 & 0.05 & 0.019 & 0.026 & 0.18 & 0.018 & 0.23 \\
S4 & & 0.21 & 1.20 & 1.14 & 0.15 & 0.04 & 0.028 & 0.030 & 0.14 & 0.009 & 0.15 \\
S6 & & 0.18 & 1.25 & 1.07 & 0.22 & 0.06 & 0.012 & 0.023 & 0.09 & 0.012 & 0.26 \\
S8 & & 0.18 & 1.12 & 1.15 & 0.19 & 0.05 & 0.006 & 0.019 & 0.12 & 0.016 & 0.16 \\
OW4 & & 0.21 & 1.31 & 1.25 & 0.16 & 0.02 & 0.006 & 0.031 & 0.12 & 0.010 & 0.17 \\
OW3 & EN18CrNiMo7-6 & 0.20 & 0.54 & 1.74 & 1.56 & 0.29 & 0.011 & 0.025 & 0.20 & 0.011 & 0.26 \\
OW5 & & 0.19 & 0.54 & 1.65 & 1.42 & 0.27 & 0.001 & 0.009 & 0.10 & 0.007 & 0.27 \\
OW7 & EN20NiMo9-7 & 0.20 & 0.23 & 0.38 & 2.24 & 0.67 & 0.001 & 0.082 & 0.16 & 0.004 & 0.08 \\
S9 & EN18NiCr5-4 & 0.18 & 0.78 & 1.15 & 1.41 & 0.09 & 0.001 & 0.033 & 0.13 & 0.008 & 0.31 \\
\hline
\end{tabular}


Table 4 Limits according to DIN EN ISO 683-3 [32] and for steel batch EN20NiMo9-7 according to the material inspection document of the steel manufacturer

\begin{tabular}{|c|c|c|c|c|c|c|c|c|c|c|c|}
\hline & & \multicolumn{10}{|c|}{ Limits in mass- $\%$} \\
\hline & & $C$ & $M n$ & $\mathrm{Cr}$ & $\mathrm{Ni}$ & Mo & $S$ & $A l$ & $\mathrm{Cu}$ & $P$ & $S i$ \\
\hline \multirow[t]{2}{*}{ EN20MnCr5 } & Max & 0.22 & 1.40 & 1.30 & - & - & 0.035 & - & - & 0.025 & 0.40 \\
\hline & Min & 0.17 & 1.10 & 1.00 & - & - & - & - & - & - & - \\
\hline \multirow[t]{2}{*}{ EN18CrNiMo7-6 } & Max & 0.21 & 0.90 & 1.80 & 1.70 & 0.35 & 0.035 & - & - & 0.025 & 0.40 \\
\hline & Min & 0.15 & 0.50 & 1.50 & 1.40 & 0.25 & - & - & - & - & - \\
\hline \multirow[t]{2}{*}{ EN20NiMo9-7 } & Max & 0.21 & 0.30 & 0.40 & 2.35 & 0.70 & 0.002 & - & - & 0.025 & 0.10 \\
\hline & Min & 0.18 & 0.22 & 0.35 & 2.25 & 0.67 & - & - & - & - & - \\
\hline \multirow[t]{2}{*}{ EN18NiCr5-4 } & Max & 0.21 & 0.90 & 1.20 & 1.50 & - & 0.035 & - & - & 0.025 & 0.40 \\
\hline & Min & 0.16 & 0.60 & 0.90 & 1.20 & - & - & - & - & - & - \\
\hline
\end{tabular}

Fig. 9 provides a first impression of the degree of cleanliness of the steel batches. The values were determined according to ISO 4967, Method A [9]. The steel batches OW7 und S9 show the lowest cleanliness index and therefore the highest degree of cleanliness. Steel batches OW1, S4 and OW3 show values above five, while the values for the other steel batches are in between.

The chemical compositions of all variants were in accordance with the specifications in [32]. Table 3, 4 and 5 provide a brief overview.

Fig. 10 gives a first impression of the crack area characteristics of tooth root failures due to a crack initiation below the surface at a non-metallic inclusion in case-hardened, shot-peened gears made out of these ultra-clean gear steels. The fisheye (encircled red) is clearly visible. The general crack area characteristics are similar to these of case-hardened, shot-peened gears made out of common and clean gear steel grades (c.f. [25]).

However, the crack area characteristics of these fisheye failures were not analyzed in detail or published so far. Therefore, in the course of this publication, the fisheye failures, which have occurred, were examined thoroughly in Sect. 5 following the approach in Sect. 4. For the characterization, a scanning electron microscope "CamScan4" with an "Oxford" EDX detector and an optical high-resolution 3D measurement system (Alicona InfiniteFocus [33]) were used. Table 6 shows an overview of the database of fisheye failures for this publication.

In industrial applications, mainly the size and the chemical composition of the non-metallic inclusion are characterized. It is also possible that the fracture surface is damaged, or the failed tooth cannot be found in a broken gearbox. Therefore, in addition, a damage assessment of fisheye fail- ures on the fracture surface on the broken tooth and on the gear is done in Sect. 6 to investigate if differences are present between both fracture surfaces.

\section{Analytical approach for fisheye fracture characterization}

In the following, an analytical approach for the fisheye fracture characterization is given. It is shown, which chemical elements and geometrical parameters of the non-metallic inclusion are determined. The determined geometrical parameters of the fisheye is displayed, as well. Furthermore, an approach for the determination of the area of the nonmetallic inclusion and a definition of the area of the fisheye in this publication are presented.

The chemical composition of the non-metallic inclusions in gear steels was determined using an energydispersive X-ray (EDX). The following chemical elements were determined: carbon (C), oxygen (O), magnesium $(\mathrm{Mg})$, aluminum $(\mathrm{Al})$, silicon $(\mathrm{Si})$, sulfur $(\mathrm{S})$, calcium $(\mathrm{Ca})$, chromium $(\mathrm{Cr})$, manganese $(\mathrm{Mn})$, iron $(\mathrm{Fe})$, nickel $(\mathrm{Ni})$ and molybdenum (Mo).

Fig. 11 shows an overview of the determined geometrical parameters of the fisheye fractures in the case that the nonmetallic inclusion consists of one or more than one particle:

- Length of the fisheye $\left(l_{\text {Fisheye }}\right)$

- Width of the fisheye ( $\mathrm{w}_{\text {Fisheye }}$ )

- Length of the NMI $\left(1_{\mathrm{NMI}}\right)$

- Width of the NMI ( $\left.\mathrm{w}_{\mathrm{NMI}}\right)$

- Distance from the surface of the NMI $\left(\mathrm{d}_{\mathrm{NMI}}\right)$

Table 5 Total oxygen content of the ultra-clean steel batches

\begin{tabular}{|c|c|c|c|c|c|c|c|c|}
\hline Alloy system & $\mathrm{MnCr}$ & & & & $\mathrm{CrNiN}$ & & NiMo & $\mathrm{NiCr}$ \\
\hline$\overline{\text { Variant }}$ & OW1 & $S 4$ & $S 8$ & OW4 & OW3 & OW5 & OW7 & $S 9$ \\
\hline $\mathrm{O}_{\text {total }}$ in ppm & 14 & Not determined & & 9 & 14 & 18 & 6 & 13 \\
\hline
\end{tabular}



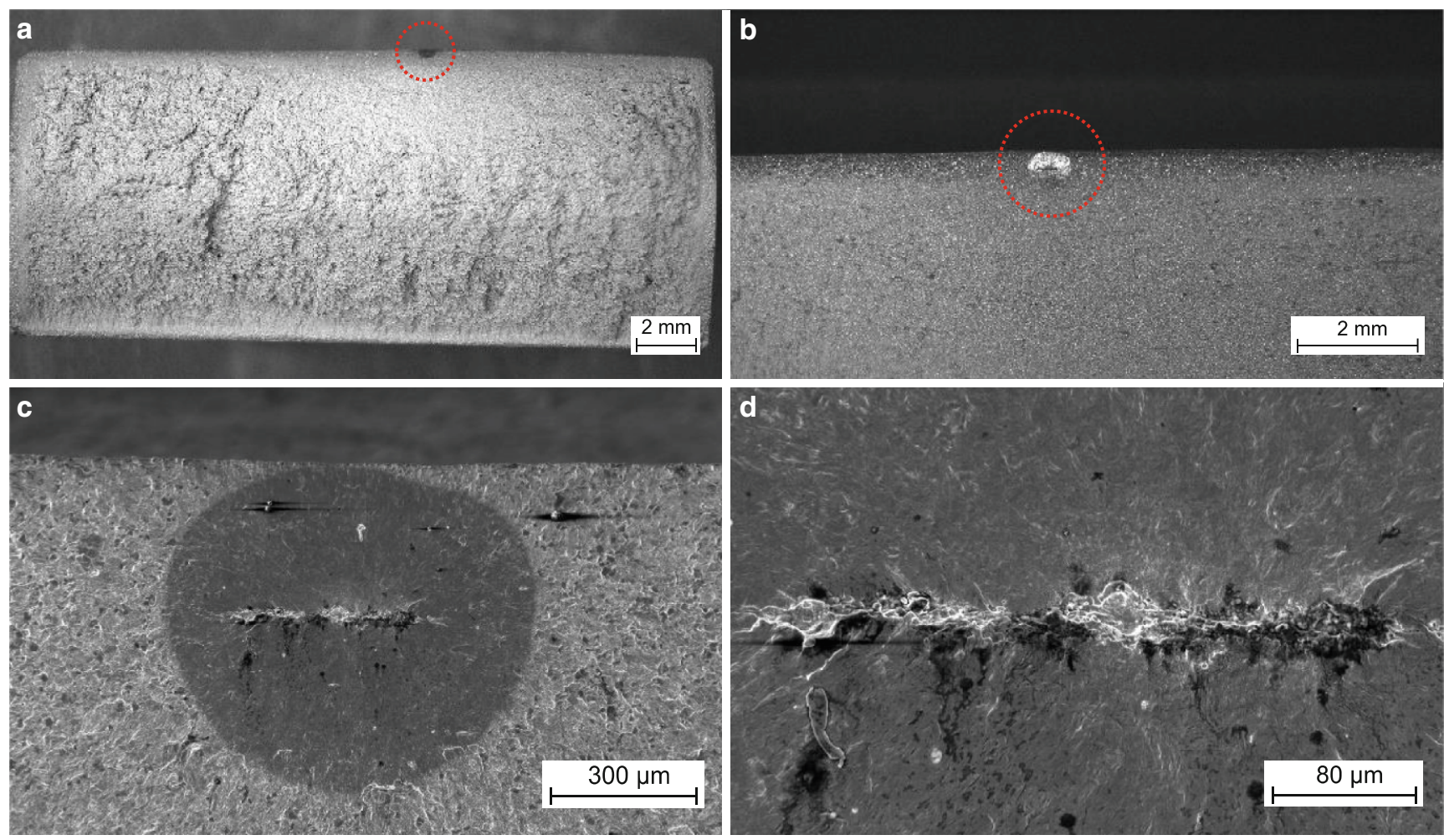

Fig. 10 First impression of the crack area characteristics of one exemplary fisheye fracture in the tooth root fillet of gears (using the example of variant OW3, gear size $m_{n}=5 \mathrm{~mm}$ ). a Overview (fisheye is circled). b Overview (fisheye is circled). c SEM-image of the fisheye. $\mathbf{d}$ SEM-image of the non-metallic inclusion

In the case that the non-metallic inclusion consists of one particle, the geometrical center of the particle is used to determine the distance from the surface. If the non-metallic inclusion consists of two or more particle, an assumed geometrical center of all particles is used. In the case of two or more particles, to determine the length and width of the non-metallic inclusion, an overall length and width is used that includes all particles (see Fig. 11b).

In a previous publication [27] the area of the non-metallic inclusion is determined as presented in Fig. 12. According to this method, not only the area of the non-metallic inclusion but also part of the area between the inclusion particles is measured as well. This results in an overestimation of the inclusion area. Furthermore, a proper determination of the area of the ODA is not possible.

According to steel test specification (SEP) 1571 parts 1 to 3 [34], a non-metallic inclusion consists of one or more particles. To determine the area of the NMI, the area of each particle is considered. Within this publication, this approach is used; see Fig. 13 and Eq. 2. The particle area was hereby derived from the measured circumference of the particle.

Inclusion particles, which are not directly involved in the crack initiation, can be found in the fisheye, especially for stringers; c.f. Fig. 14. Such particles should not be considered in the determination of the inclusion area; see Eq. 3 As a decision criterion, the surface structure around the inclu- sion can be chosen. Usually, the surface structure around the non-relevant particle is slightly different from the surface structure around the inclusions involved in the crack initiation. The crack initiation is typically in the region of a finer microstructure around the NMI; c.f. Fig. 6. Furthermore, if the particle is near the boundary of the fisheye it should be non-relevant for the crack initiation.

$A_{\mathrm{NMI}}=\sum_{1}^{i} A_{\text {particle }, i}$
$A_{\text {Particle,non }} \notin \sum_{1}^{i} A_{\text {particle }, i}$

A few non-metallic inclusions were longer than the fisheye itself; c.f. Fig. 15 and 16. In this case, the following assumption for the area of the NMI was made: the areas at the border and outside of the fisheye should not be relevant for the crack initiation. Therefore, only the area of the NMI assumed to be relevant for crack initiation was determined.

Table 6 Database of fisheye failures in this publication

\begin{tabular}{ll}
\hline Alloy system & Number of fisheye failures \\
\hline $\mathrm{MnCr}$ & 75 \\
$\mathrm{NiCr}$ & 8 \\
$\mathrm{CrNiMo}$ & 21 \\
$\mathrm{NiMo}$ & 3 \\
In total & 107 \\
\hline
\end{tabular}



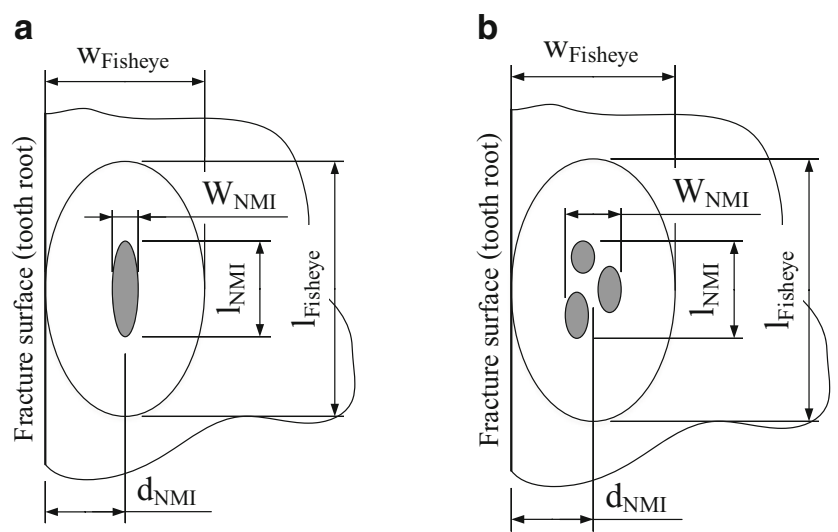

Fig. 11 Determined geometrical parameters of fisheye and non-metallic inclusion in the case that a non-metallic inclusion consists of $\mathbf{a}$ one; or $\mathbf{b}$ more than one particle

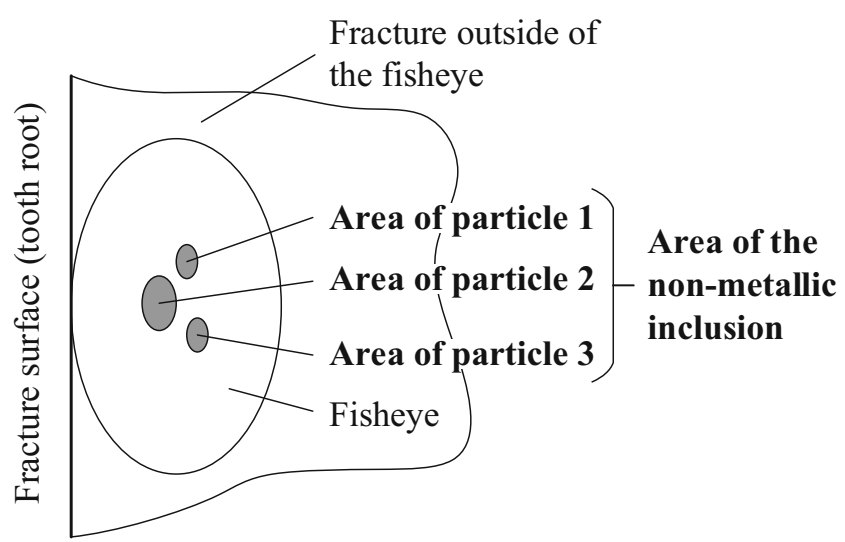

Fig. 13 Determination of the area of the non-metallic inclusion based on particles

If an ODA is present, the relevant area of the NMI is in the region of the ODA. The length of the ODA could be either longer (see Fig. 15a) or shorter (see Fig. 15b) than the length of the NMI. The crack initiation is in the region of a finer surface structure around the NMI. An assumption of the relevant area can be made based on the finer surface structure around the NMI, which is exemplarily shown in Fig. 6 in detail.

If no ODA is present, determining the relevant area of the NMI relevant for crack initiation may be more difficult; c.f. Fig. 16. The differences in the surface structure between the crack initiation area and the crack growth area in the fisheye are slightly more similar and not as pronounced when there is an ODA present. However, a subjective distinction is sometimes not possible. Therefore, often an assumption must be made based on the based on professional experience.

The area of the ODA is the sum of the area of the dark area and the NMI; see Eq. 4. This follows the approach according to Murakami [11] (c.f. Eq. 1). Fig. 17 shows two

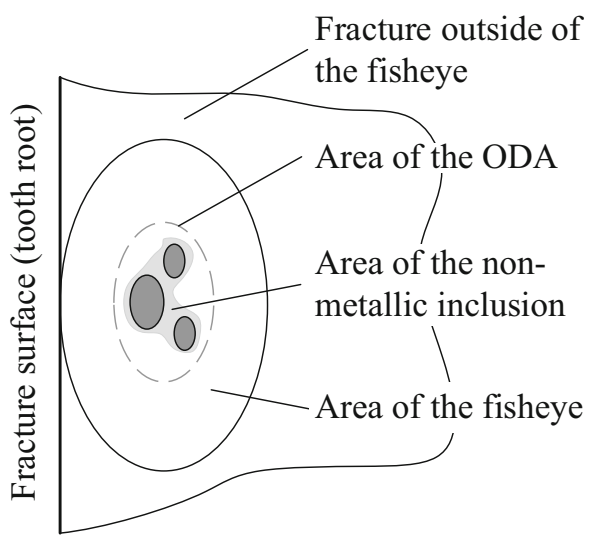

Fig. 12 Determination of the area of a non-metallic inclusion in [27]

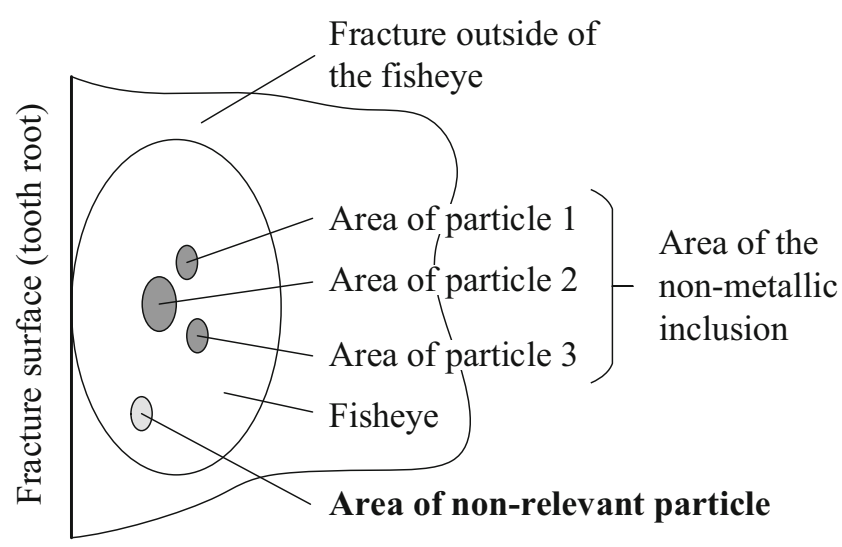

Fig. 14 Non-relevant inclusion particle

examples, where the dark area completely includes the NMI and where the dark area partly includes the NMI.

$A_{\mathrm{ODA}}=A_{\mathrm{NMI}}+A_{\text {Dark area }}$

The area of the total fisheye consists of the areas of the NMI, the ODA, and the rest of the area inside the fisheye itself; see Eq. 5.

$A_{\text {Fisheye }}=A_{\mathrm{ODA}}+A_{\mathrm{NMI}}+A_{\text {Fisheye,rest }}$

\section{Fracture analysis of fisheye failures in the tooth root fillet of shot-peened gears}

In the following a fracture analysis of fisheye failures in the tooth root fillet of shot-peened gears is made. The analysis follows the approach in Sect. 4.

In $\mathrm{MnCr}$-alloyed steels, fisheye failures are caused mainly by manganese sulfides (MnS), and in CrNiMoalloyed steels mainly by aluminum oxides $\left(\mathrm{Al}_{2} \mathrm{O}_{3}\right)$. For 
a

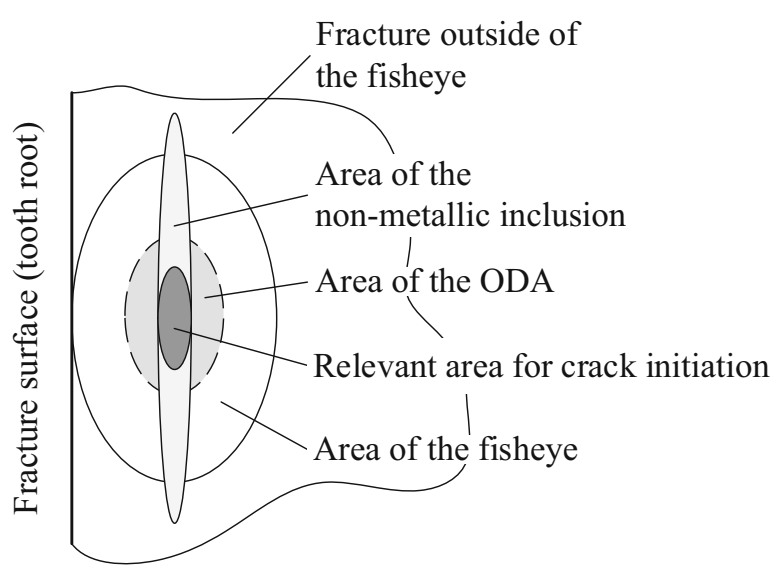

b

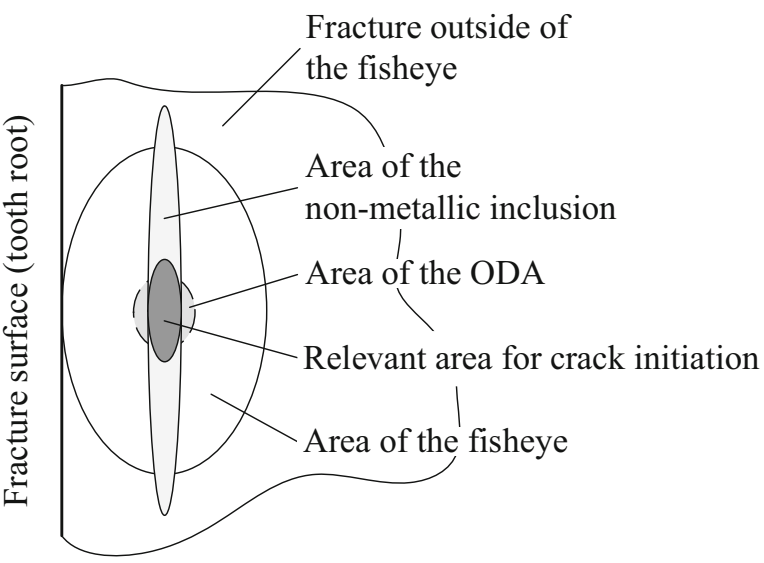

Fig. 15 Relevant area for crack initiation of the non-metallic inclusion a the length of the ODA is longer than the length of the NMI and $\mathbf{b}$ the length of the ODA is shorter than the length of the NMI

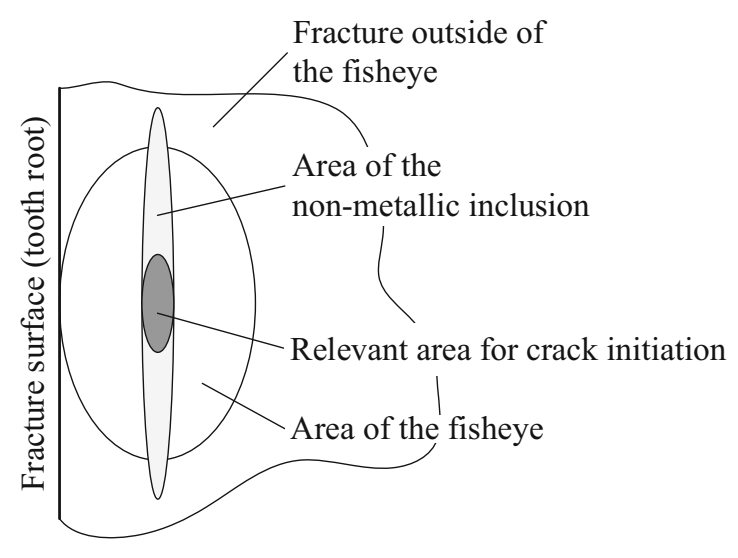

Fig. 16 Relevant area for crack initiation of the non-metallic inclusion where no ODA is present the investigated alloy systems, Table 7 shows the chemical composition and the percentage of the non-metallic inclusion, which was mainly responsible for the crack initiation. In Fig. 18 an example of a manganese sulfide inclusion is shown.

The crack initiations in $\mathrm{MnCr}$ alloyed steels, which were not at a manganese sulfide inclusions, were at aluminum oxide inclusions $(9.5 \%)$ and mixed inclusions $(3.2 \%)$. In CrNiMo alloyed steels $20 \%$ of the crack initiations were at manganese sulfide inclusions and $26.7 \%$ at mixed inclusions. $12.5 \%$ of the remaining crack initiations in the $\mathrm{NiCr}$ alloyed steel were at mixed inclusions. In the NiMo alloyed steel all three failures were due to an aluminum oxide inclusion.

None of the analyzed non-metallic inclusions were manganese sulfide or aluminum oxide inclusions only. In every non-metallic inclusion, minor elements were detected, such as silicon $(\mathrm{Si})$, copper $(\mathrm{Cu})$, molybdenum $(\mathrm{Mo})$, and calcium $(\mathrm{Ca})$. Furthermore, the analytical investigation regard- a

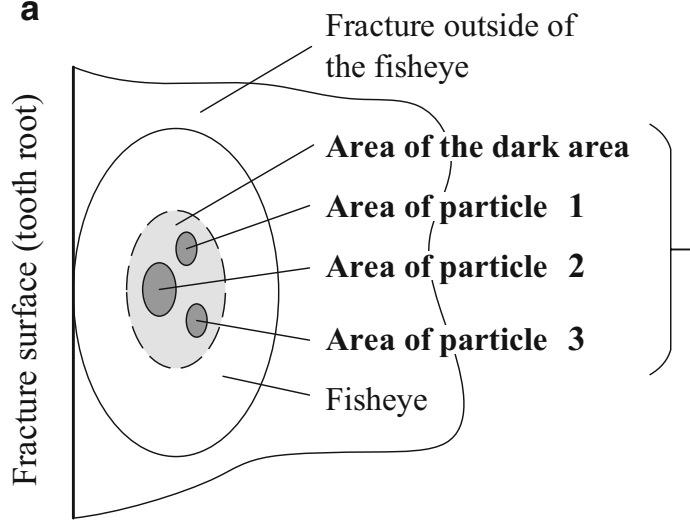

b

Area of the ODA

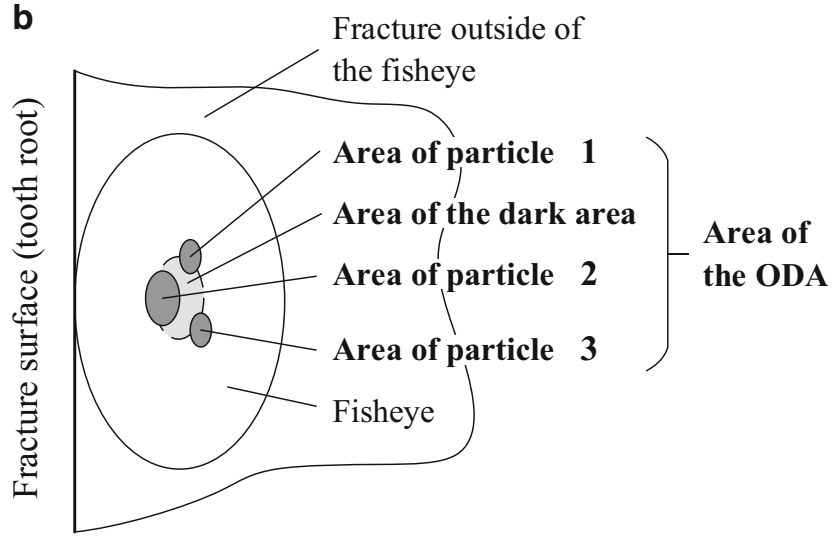

Fig. 17 Area of the ODA a dark area completely includes the NMI b dark area partly includes the NMI 
Table 7 Chemical composition of the NMI, which was mainly responsible for crack initiation, and percentage

\begin{tabular}{ll}
\hline Alloy system & Chemical composition of NMI (percentage) \\
\hline $\mathrm{MnCr}$ & Manganese sulfide $(\mathrm{MnS})(87.3 \%)$ \\
$\mathrm{CrNiMo}$ & Aluminum oxide $\left(\mathrm{Al}_{2} \mathrm{O}_{3}\right)(53.3 \%)$ \\
$\mathrm{NiCr}$ & Aluminum oxide $\left(\mathrm{Al}_{2} \mathrm{O}_{3}\right)(87.5 \%)$ \\
$\mathrm{NiMo}$ & Aluminum oxide $\left(\mathrm{Al}_{2} \mathrm{O}_{3}\right)(100 \%)$ \\
\hline
\end{tabular}

ing the chemical composition showed mixed inclusions. These consisted of manganese, sulfur, aluminum, oxygen, and further minor elements. In the $\mathrm{MnCr}$ alloyed steels, the most present minor element was molybdenum (Mo). Calcium $(\mathrm{Ca})$ was the most present minor element in the CrNiMo alloyed steel. In the $\mathrm{NiCr}$ and NiMo alloyed steels the most present minor elements were calcium $(\mathrm{Ca})$ and manganese (Mn).

In Fig. 19 the measured area of the fisheye is plotted against the calculated ellipsoidal area of the fisheye according to Eq. 6. It can be seen that the area of a fisheye can be described by an ellipsoidal area using the length and the width of the fisheye. This approach should not only be applicable on gears but also on fisheye failures in general components and specimens, too. If the fisheye is circularly formed, the diameter can be used to derive a circular area; c.f. Fig. 2.

$A_{\text {Fisheye,calc }}=\pi \cdot \frac{l_{\text {Fisheye }} \cdot w_{\text {Fisheye }}}{4}$

In [27], a correlation between the area of the fisheye and the distance from the surface of the NMI was published. This correlation can be confirmed by the extended available
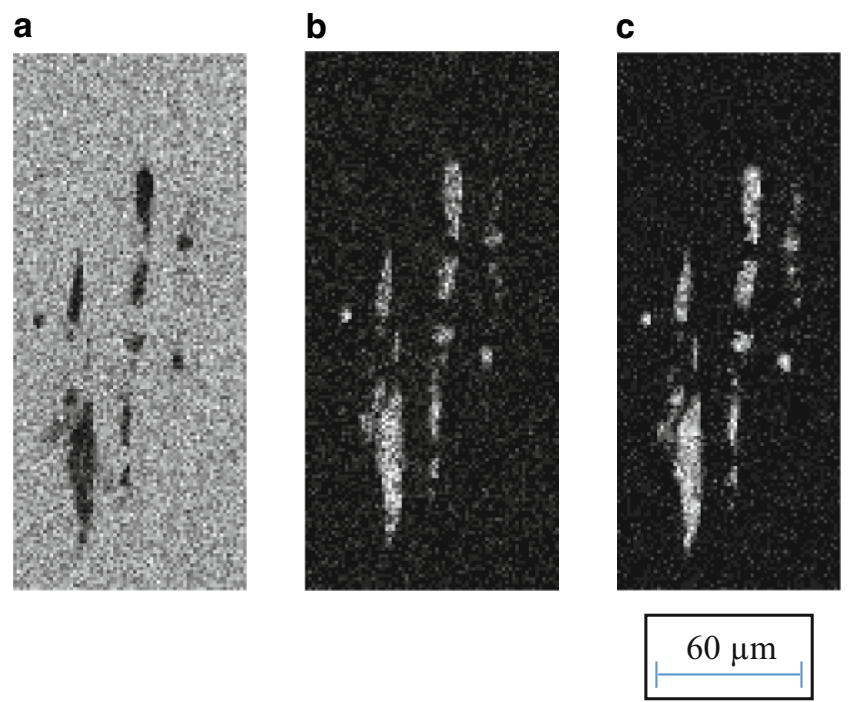

Fig. 18 Example of an EDX image of a manganese sulfide stringer inclusion in a manganese-chrome-alloyed steel. $\mathbf{a}$ iron $(\mathrm{Fe})$. b manganese (Mn). c sulfur (S) database of this publication; see Fig. 20. The greater the distance of the NMI from the surface, the larger the area of the fisheye.

In Fig. 21, the width of the NMI is plotted against its length. No clear correlation is observable. Therefore, the width and length of the NMI cannot be used to properly describe the area of the NMI. The approach based on a particle-based determination, which is used in this publication, is more appropriate when defining the area of non-metallic inclusions. In Fig. 22 the distance from the surface is plotted against the measured area of the NMI. There is no clear correlation.

Not all of the inspected fracture surfaces showed an ODA. An ODA was present in $82 \%$ of the fisheye fractures. Therefore, in the following, only the fisheye failures with an ODA are looked at in detail. In Fig. 23, the area of the NMI is plotted against the area of the ODA.

It can be seen that there is a correlation between the area of the NMI and the ODA. The ratio decreases with an increasing area of the NMI. However, no correlation between the area of the ODA and the distance from the surface of the NMI can be found; see Fig. 24.

\section{Damage assessment of fisheye failures on the fracture surface on the broken tooth and on the gear}

In the following, further investigations into possible differences on the fracture surfaces of the broken teeth and the corresponding gears were performed. Fig. 25 shows the fisheye characteristic on a broken tooth and the corresponding gear. The fisheye structures are inverse and therefore the length, width, and area can be determined on each fracture surface.

In Fig. 26, a comparison of the determined areas of a non-metallic inclusion on the fracture surface on a broken tooth and the corresponding gear are shown. It can be seen that the determined areas differ from each other. The area of the NMI on the broken tooth is $1271 \mu \mathrm{m}^{2}$, whereas it is $1088 \mu \mathrm{m}^{2}$ on the corresponding gear, which is approximately a difference of $15 \%$. The available database shows that in $20 \%$ of the cases, the area on the broken tooth can be up to $20 \%$ larger than the area on the corresponding gear. In the other cases, the difference is approximately 2 to $10 \%$ and is almost equally divided between broken tooth and corresponding gear. Therefore, the area of the non-metallic inclusion should be determined on both fracture surfaces and the biggest area (worst-case) should be used for further analysis and local calculation approaches.

Fig. 27 shows EDX images of the fracture surfaces of a manganese sulfide and an aluminum oxide inclusion. A manganese sulfide inclusion is softer than the steel ma- 
Fig. 19 Measured area plotted against the calculated ellipsoidal area of the fisheye a overview b detail view in the range of $300,000 \mu \mathrm{m}^{2}$

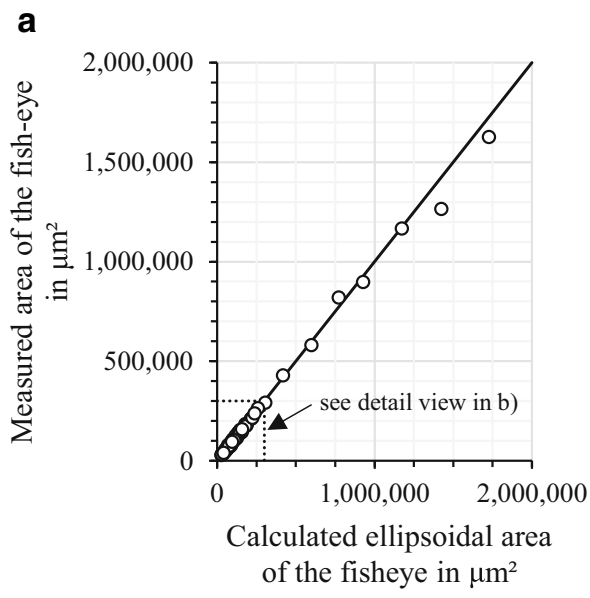

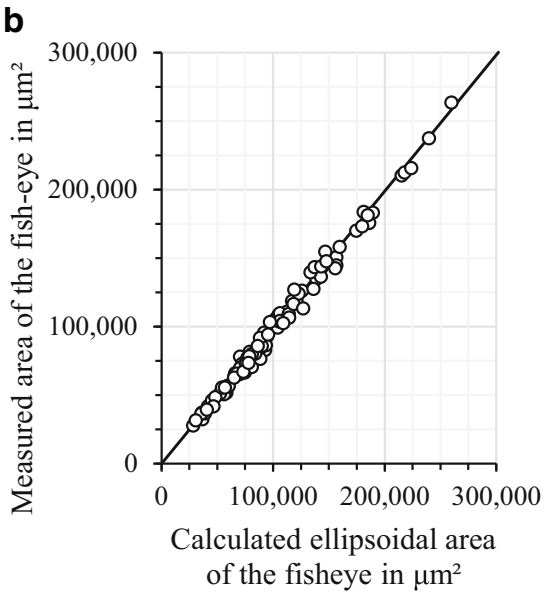

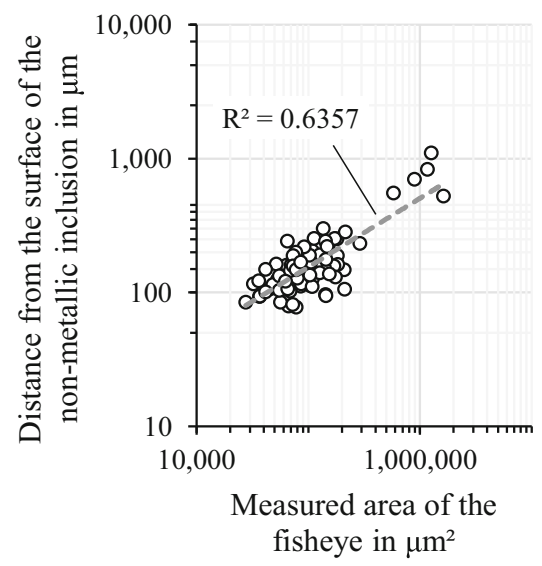

Fig. 20 Distance from the surface of the non-metallic inclusion plotted against the area of fisheye

trix and has strong bonding to the steel matrix, whereas an aluminum oxide is harder and merely has weak bonding. Some of these characteristics can be seen in Fig. 27. The manganese sulfide inclusion is almost equally divided between the fracture surfaces. It can be assumed that the separation of the NMI was at an internal crack. On the other hand, the aluminum oxide inclusion is mainly on the fracture surface of the gear. Here, it can be assumed that the main separation was between the inclusion and the steel matrix. The conclusion is that for a proper determination of the chemical composition of an NMI, both fracture surfaces should be considered.

\section{Discussion of the results}

So far, no systematic extensive studies on failure characteristics in the tooth root fillet of case-hardened, shot-peened gears made out of case-hardened wrought steels, where the cracks have been initiated from non-metallic inclusions below the surface, can be found in the literature. Therefore, in this publication an extended fracture analysis was performed to ensure the quality of the input data for a presented model approach and to further extend the model approach in the medium term.

All of the shot-peened, case-hardened gears made out of ultra-clean gear steels failed in the range of the endurance limit mainly due to fisheye failures in the tooth root. Even the steel grades OW7 and S9, which show the highest degree of cleanliness, failed mainly due to a crack initiation at a non-metallic inclusion. It can be concluded, that even with ultra-clean gear steels a crack initiation at a non-metallic inclusion cannot be prevented in the range of the endurance limit of shot-peened, case-hardened gears.

The different alloy systems failed due to different types of non-metallic inclusions. In $\mathrm{MnCr}$ alloyed steels the nonmetallic inclusion, which was mainly responsible for crack initiation, was a manganese sulfide, whereas in the other three steel grades aluminum oxide inclusions were mainly responsible. However, the proportion of failures at aluminum oxide inclusions is also different for these three steel grades. In every non-metallic inclusion different minor elements were present. In addition, in the $\mathrm{MnCr}, \mathrm{CrNiMo}$ and $\mathrm{NiCr}$ alloyed steels some mixed inclusions were responsible for the crack initiation. Only in the NiMo alloyed steel all three failures were due to an aluminum oxide inclusion.

The area of a fisheye in these shot-peened, case-hardened gears can be described by an ellipsoidal area using the length and the width of the fisheye. This is in accordance to Fig. 3, where the fisheyes of heat-treated and shot-peened specimens had an ellipsoidal form.

One correlation found is that the greater the distance of the non-metallic inclusion from the surface, the larger the area of the fisheye. However, no clear correlation is observable between the width and the length of the nonmetallic inclusions. This can be attributed to the fact that in the available database, a large number of the non-metallic inclusions are stringer inclusions. These stringer inclusions consists of two or more particles and are counted as one 


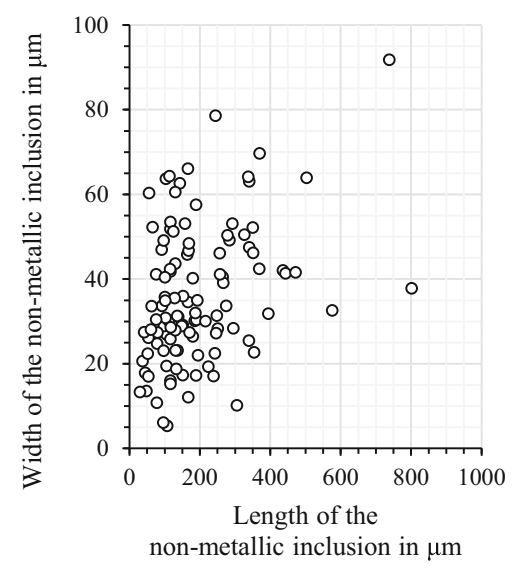

Fig. 21 Width plotted against the length of the non-metallic inclusion

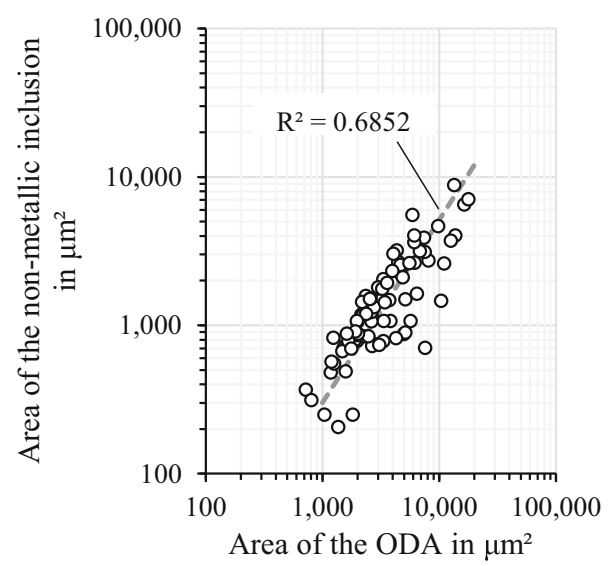

Fig. 23 Area of the non-metallic inclusion plotted against the area of the ODA

non-metallic inclusion, because the distance between these particles is very small. Each particle has its own length and width. However, no correlation between the absolute length and absolute width of the non-metallic inclusion is possible, due to the stringer characteristic; c.f. Fig. 10b. The distance from the surface and the measured area of the non-metallic inclusion do not correlate, as well. Therefore, the area of the NMI cannot be derived from the distance of the NMI from the surface.

An ODA was present in $82 \%$ of the fisheye fractures. There is a correlation between the area of the NMI and the ODA. The ratio decreases with an increasing area of the NMI. Employing this correlation, the area of the ODA can be estimated based on the area of the NMI. Murakami derived in [11] a master-curve of the ODA, which correlates the increase of the ODA area in comparison to the NMI area as a function of the load cycles. These two correlations of the ODA should be analyzed in more detail in further work. However, no correlation between the area of the ODA and the distance from the surface of the NMI can be found.

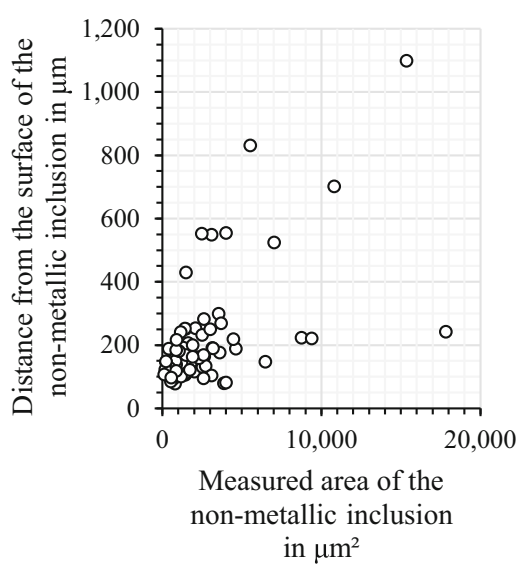

Fig. 22 Distance from the surface plotted against the measured area of the non-metallic inclusion

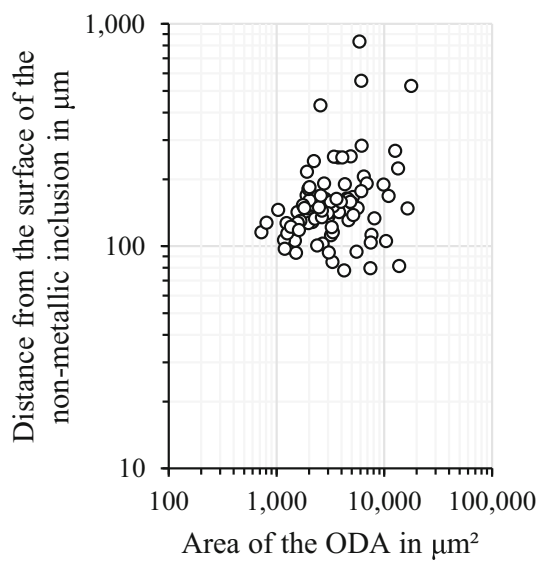

Fig. 24 Distance of the non-metallic inclusion plotted against the area of the ODA

The investigations regarding possible differences on the fracture surfaces of the broken teeth and the corresponding gears showed that the length, width, and area of the fisheye can be determined on each fracture surface. However, the area of the non-metallic inclusion and the chemical composition of an NMI should be determined on both fracture surfaces. In industrial practice, it is possible that one of the fracture surfaces cannot be characterized after a tooth root failure, be it for reasons of a damaged fracture surface or a missing tooth. In the course of this publication, it has been shown that the area of the NMI on both fracture surfaces can differ by up to $20 \%$.

\section{Conclusions}

The summarized conclusions are:

- None of the analyzed non-metallic inclusions were manganese sulfide or aluminum oxide inclusions only. In 
Fracture surface (tooth root)

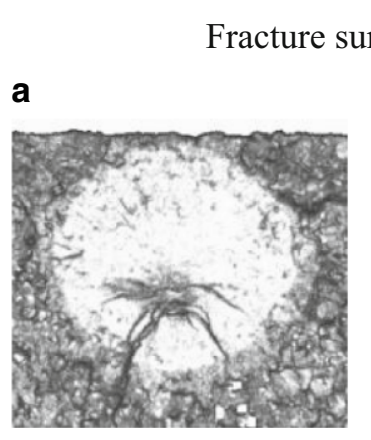$$
\text { b }
$$
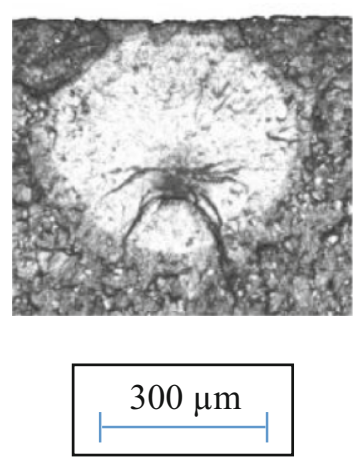

Fig. 25 Fisheye characteristic on both fracture surfaces. a broken tooth.b corresponding gear a

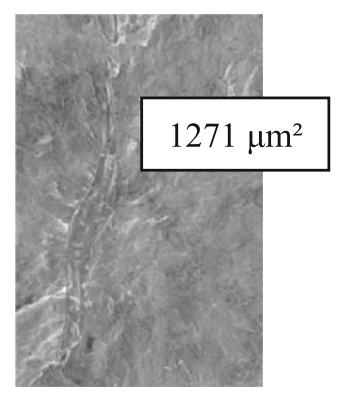

b

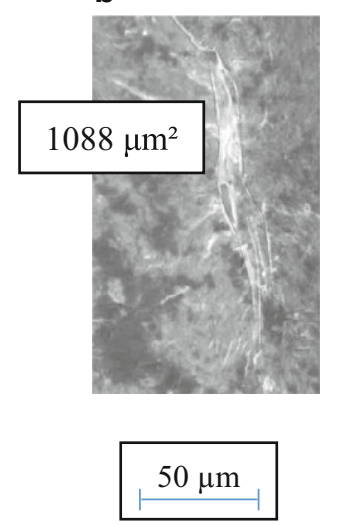

Fig. 26 Comparison of the areas of a non-metallic inclusion on both fracture surfaces. a broken tooth. b corresponding gear

Table 8 Nomenclature

\begin{tabular}{|c|c|c|}
\hline Symbol & Unit & Description \\
\hline$\overline{A_{\text {Dark area }} A_{1}}$ & $\mu \mathrm{m}^{2}$ & Area of the dark area \\
\hline$A_{\text {Fisheye, rest }}$ & $\mu \mathrm{m}^{2}$ & $\begin{array}{l}\text { Rest of the area inside the fish- } \\
\text { eye, which is not the ODA or } \\
\text { NMI }\end{array}$ \\
\hline$A_{\text {Fisheye,calc }}$ & $\mu \mathrm{m}^{2}$ & $\begin{array}{l}\text { Calculated ellipsoidal area of } \\
\text { the fisheye }\end{array}$ \\
\hline $\mathrm{A}_{\mathrm{NMI}} \mathrm{A}_{0}$ & $\mu \mathrm{m}^{2}$ & $\begin{array}{l}\text { Area of the non-metallic incul- } \\
\text { sion }\end{array}$ \\
\hline$A_{\mathrm{ODA}}$ & $\mu \mathrm{m}^{2}$ & $\begin{array}{l}\text { Area of the optically dark area } \\
\text { (ODA) }\end{array}$ \\
\hline$A_{\text {particle, } i}$ & $\mu \mathrm{m}^{2}$ & Area of particle $\mathrm{i}$ \\
\hline$A_{\text {Particle,non }}$ & $\mu \mathrm{m}^{2}$ & $\begin{array}{l}\text { Area of a non-relevant inclusion } \\
\text { particle }\end{array}$ \\
\hline $\mathrm{d}_{\mathrm{NMI}}$ & $\mu \mathrm{m}$ & $\begin{array}{l}\text { Distance of the NMI from the } \\
\text { surface }\end{array}$ \\
\hline$l_{\text {Fisheye }}$ & $\mu \mathrm{m}$ & Length of the fisheye \\
\hline$l_{\mathrm{NMI}}$ & $\mu \mathrm{m}$ & Length of the NMI \\
\hline WFisheye & $\mu \mathrm{m}$ & Width of the fisheye \\
\hline $\mathrm{w}_{\mathrm{NMI}}$ & $\mu \mathrm{m}$ & Width of the NMI \\
\hline
\end{tabular}
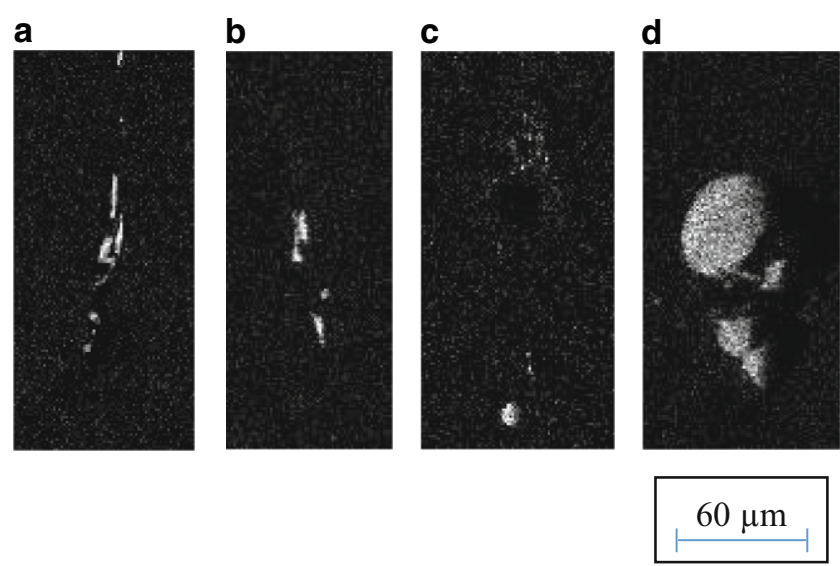

Fig. 27 EDX analysis of a a, b manganese sulfide and an $\mathbf{c}$, $\mathbf{d}$ aluminum oxide inclusion on both fracture surfaces. $\mathbf{a}$ broken tooth. $\mathbf{b}$ corresponding gear. $\mathbf{c}$ broken tooth. $\mathbf{d}$ corresponding gear

every non-metallic inclusion, minor elements were detected.

- The area of a fisheye can be described by an ellipsoidal area using the length and the width of the fisheye.

- The greater the distance from the surface of the nonmetallic inclusion, the larger the area of the fisheye.

- No clear correlation is observable between the width and the length of non-metallic inclusions. This can be attributed to the fact that in the available database, a large number of the non-metallic inclusions are stringer inclusions.

- An approach based on a particle-based determination, which is used in this publication, is more appropriate as the approach from a previous publication [27] when defining the area of non-metallic inclusions.

- Using the applied approach a proper characterization of the area of the ODA is possible.

- An ODA was present in $82 \%$ of the fisheye fractures.

- No clear correlation is observable between the distance from the surface and the measured area of the non-metallic inclusion.

- A correlation between the area of the NMI and the ODA is apparent. Employing this correlation, the area of the ODA can be estimated based on the area of the NMI.

- No correlation between the area of the ODA and the distance from the surface of the NMI can be found.

Further investigations into possible differences on the fracture surfaces of the broken teeth and the corresponding gears were performed. The summarized conclusions are:

- The length, width, and area of the fisheye can be determined on each fracture surface

- The area of the non-metallic inclusion should be determined on both fracture surfaces 
- For a proper determination of the chemical composition of an NMI, both fracture surfaces should be considered

\section{Summary and subsequent steps}

In shot-peened, case-hardened gears, fisheye failures can occur. However, in standardized gear calculation methods a consideration of a crack initiation below the surface at non-metallic inclusions is not possible, yet. Therefore, extended model approaches are still necessary. However, the reliability of such model approaches depends on the quality of the input data, which can be ensured with a proper fracture surface analysis. As a result, the aim of this paper was to characterize the crack area characteristics in the tooth root fillet of case-hardened, shot-peened gears in detail according to a presented approach to further extend the presented extended model approach in the medium term.

It was shown that various aspects have to be taken in account when characterizing fisheye failures. In the literature different and sometimes not fully documented assumptions and approaches have been used so far to document fisheye characteristics. Therefore, the applied approach for fracture analysis was documented in detail in this publication. In addition, so far, no systematic extensive studies on fisheye failure characteristics in the tooth root fillet of casehardened, shot-peened gears can be found in the literature. Therefore, in this publication an extended fracture analysis was performed following the presented approach and several conclusions could be drawn.

The main findings of this paper with regard to the crack area characteristics of fisheye failures are:

- The applied approach based on a particle-based determination is more appropriate, when defining the area of non-metallic inclusions.

- Using the applied approach a proper characterization of the area of the ODA is possible.

- Some characteristics can be determined on one fracture surface and others should be determined on both fracture surfaces.

The area of the non-metallic inclusion is usually the main parameter for local calculation approaches for predicting the tooth root bending strength (c.f. $[6,21])$. It would be a great benefit, if in all future publications the chosen approach for the characterization of fisheye failures would be documented. This will allow a comparison and holistic use of the databases in the future and therefore contributes to an advanced understanding of the fisheye failure mechanism in gears.

In Fig. 25 several lines respectively steps at the nonmetallic inclusion can be seen, which were not looked at in detail in the framework of this publication. Both steps start at the non-metallic inclusion, which lies here horizontally, and then run almost vertically to the boundary of the fisheye in this example. Therefore, in subsequent work, an extended fracture analysis of fisheye failures will be performed regarding the presented steps at the non-metallic inclusion and possible further characteristics. In addition, the chemical composition and morphology of non-metallic inclusions in ultra-clean gear steels are also considered in more detail in subsequent work. The aim is to further understand the formation and propagation of cracks at nonmetallic inclusions and in fisheyes. Moreover, based on the results of the publication, the presented extended model approach will be further developed in subsequent work. In particular, the ODA will be taken into account.

In the long term, the aim is to provide a basis for countermeasures in steelmaking and gear manufacturing that can be applied to avoid the initiation of subsurface cracks at non-metallic inclusions and to achieve higher load carrying capacities.

\section{Nomenclature}

The nomenclature is shown in Table 8 .

Acknowledgements The underlying research work [29] was equally funded by the "Arbeitsgemeinschaft industrieller Forschungsvereinigungen e. V. (AiF)", the German Federal Ministry of Economics and Technology (BMWi, IGF no. 16662 N) and the "Forschungsvereinigung Antriebstechnik e.V. (FVA)". The results shown in this work were taken from the FVA research project 293 III "Späte Zahnfußbrüche / Reinheitsgrad" [29]. More detailed information on the influence of non-metallic inclusions is given in the final report.

The underlying research work [30] was equally funded by the "Forschungsvereinigung der Arbeitsgemeinschaft der Eisen und Metall verarbeitenden Industrie e. V. (AVIF)" (A 305/S 0024/10235/16) and the "Forschungsvereinigung Antriebstechnik e. V. (FVA)". The results shown in this work were taken from the FVA research project 293 IV "Späte Zahnfußbrüche/Reinheitsgrad II" [30]. More detailed information on the influence of non-metallic inclusions, especially in the very high cycle range, is given in the final report.
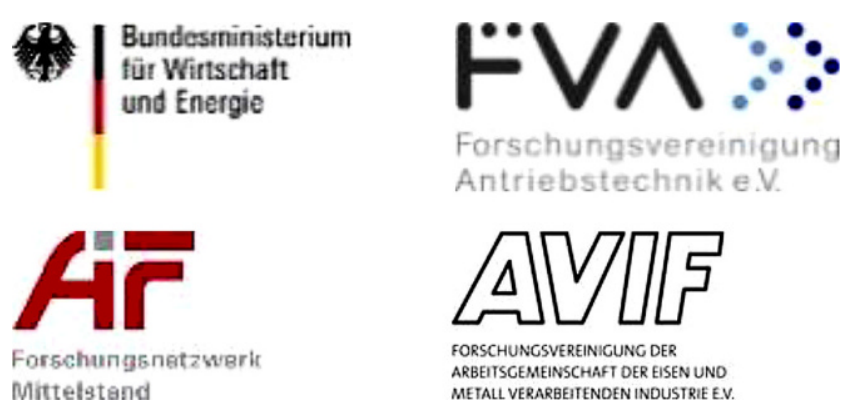

Funding Open Access funding enabled and organized by Projekt DEAL. 
Open Access This article is licensed under a Creative Commons Attribution 4.0 International License, which permits use, sharing, adaptation, distribution and reproduction in any medium or format, as long as you give appropriate credit to the original author(s) and the source, provide a link to the Creative Commons licence, and indicate if changes were made. The images or other third party material in this article are included in the article's Creative Commons licence, unless indicated otherwise in a credit line to the material. If material is not included in the article's Creative Commons licence and your intended use is not permitted by statutory regulation or exceeds the permitted use, you will need to obtain permission directly from the copyright holder. To view a copy of this licence, visit http://creativecommons.org/licenses/by/4. $0 /$.

\section{References}

1. AGMA Standard (2004) Fundamental rating factors and calculation methods for involute spur and helical gear teeth (ANSI/AGMA 2001-D04)

2. ISO (International Organization for Standardization) Calculation of load capacity of spur and helical gears-part 1-5 (ISO 6336)

3. Shiozawa K, Murai M, Shimatani Y et al (2010) Transition of fatigue failure mode of Ni-Cr-Mo low-alloy steel in very high cycle regime. Int J Fatigue 32:541-550. https://doi.org/10.1016/j. ijfatigue.2009.06.011

4. Nishijima S, Kanazawa K (1999) Stepwise SN curve and fisheye failure in gigacycle fatigue. Fat Frac Eng Mat Struct 22:601-607. https://doi.org/10.1046/j.1460-2695.1999.00206.x

5. Sakai T (2009) Review and prospects for current studies on very high cycle fatigue of metallic materials for machine structural use. JMMP 3:425-439. https://doi.org/10.1299/jmmp.3.425

6. Murakami Y (2019) Metal fatigue: Effects of small defects and nonmetallic inclusions, 2nd edn. Elsevier, Amsterdam

7. Murakami Y, Nomoto T, Ueda T (1999) Factors influencing the mechanism of superlong fatigue failure in steels. Fat Frac Eng Mat Struct 22:581-590. https://doi.org/10.1046/j.1460-2695.1999. 00187.x

8. Shiozawa K, Lu L (2002) Very high-cycle fatigue behaviour of shot-peened high-carbon-chromium bearing steel. Fatigue Fract Eng Mater Struct 25:813-822. https://doi.org/10.1046/j.1460-2695. 2002.00567.x

9. ISO (International Organization for Standardization) (2013) SteelDetermination of content of non-metallic inclusions-Micrographic method using standard diagrams (ISO 4967)

10. Murakami Y, Yokoyama NN, Nagata J (2002) Mechanism of fatigue failure in ultralong life regime. Fat Frac Eng Mat Struct 25:735-746. https://doi.org/10.1046/j.1460-2695.2002.00576.x

11. Murakami Y, Yamashita Y (2014) Prediction of life and scatter of fatigue failure originated at nonmetallic inclusions. Procedia Eng 74:6-11. https://doi.org/10.1016/j.proeng.2014.06.214

12. Sakai T, Oguma N, Nakagawa A et al (2017) Formation mechanism of fine granular area (FGA) around interior inclusion at crack initiation site in very high cycle fatigue. In: Zimmermann M, Christ H-J (eds) VHCF7: Seventh International Conference on Very High Cycle Fatigue: July 3-5, 2017, Dresden, Germany. Siegener Werkstoffkundliche Berichte, Siegen, pp 57-62

13. Ochi Y, Matsumura T, Masaki K et al (2002) High-cycle rotating bending fatigue property in very long-life regime of high-strength steels. Fatigue Frac Eng Mat Struct 25:823-830. https://doi.org/10. 1046/j.1460-2695.2002.00575.x

14. Shiozawa K, Morii Y, Nishino S et al (2006) Subsurface crack initiation and propagation mechanism in high-strength steel in a very high cycle fatigue regime. Int J Fatigue 28:1521-1532. https://doi. org/10.1016/j.ijfatigue.2005.08.015
15. Makino T (2008) The effect of inclusion geometry according to forging ratio and metal flow direction on very high-cycle fatigue properties of steel bars. Int J Fatigue 30:1409-1418. https://doi.org/ 10.1016/j.ijfatigue.2007.10.009

16. Nakamura T, Oguma H, Shinohara Y (2010) The effect of vacuumlike environment inside sub-surface fatigue crack on the formation of ODA fracture surface in high strength steel. Procedia Eng 2:2121-2129. https://doi.org/10.1016/j.proeng.2010.03.228

17. Tridello A, Fiocchi J, Biffi CA et al (2019) VHCF response of heattreated SLM Ti6Al4V Gaussian specimens with large loaded volume. Procedia Struct Integr 18:314-321. https://doi.org/10.1016/j. prostr.2019.08.171

18. Nakamura Y, Sakai T, Harlow D et al (2017) Probabilistic model on statistical fatigue property in very high cycle regime based on distributions of size and location of interior inclusions. In: Zimmermann M, Christ H-J (eds) VHCF7: Seventh International Conference on Very High Cycle Fatigue: July 3-5, 2017, Dresden, Germany. Siegener Werkstoffkundliche Berichte, Siegen, pp 81-86

19. Murakami Y (2002) Metal fatigue: effects of small defects and nonmetallic inclusions, 1st edn. Elsevier, Amsterdam

20. Murakami Y, Matsunaga H, Abyazi A et al (2013) Defect size dependence on threshold stress intensity for high-strength steel with internal hydrogen. Fatigue Frac Eng Mat Struct 36:836-850. https:// doi.org/10.1111/ffe. 12077

21. Fuchs D, Schurer S, Tobie T et al (2019) A model approach for considering nonmetallic inclusions in the calculation of the local tooth root load-carrying capacity of high-strength gears made of high-quality steels. Proc Inst Mech Eng Part C: J Mech Eng Sci 661:7309-7317. https://doi.org/10.1177/0954406219840676

22. Schurer S (2016) Einfluss nichtmetallischer Einschlüsse in hochreinen Werkstoffen auf die Zahnfußtragfähigkeit [eng.: influence of non-metallic inclusions in ultra-clean materials on the tooth root load-carrying capacity]. Dissertation, Technical University of Munich

23. Bretl NT (2010) Einflüsse auf die Zahnfußtragfähigkeit einsatzgehärteter Zahnräder im Bereich hoher Lastspielzahlen [eng.: influences on the tooth root load carrying capacity of case-hardened gears in the range of high load cycles]. Dissertation, Technical University of Munich

24. Stenico A (2007) Werkstoffmechanische Untersuchungen zur Zahnfußtragfähigkeit einsatzgehärteter Zahnräder [eng.: material-mechanical investigations of the tooth root load carrying capacity of case-hardened gears]. Dissertation, Technical University of Munich

25. Bretl N, Schurer S, Tobie T et al (2013) Investigations on tooth root bending strength of case hardened gears in the range of high cycle fatigue (AGMA Technical Paper 13FTM09)

26. Winkler KJ, Schurer S, Tobie T et al (2019) Investigations on the tooth root bending strength and the fatigue fracture characteristics of case-carburized and shot-peened gears of different sizes. Proc Inst Mech Eng Part C: J Mech Eng Sci. https://doi.org/10.1177/ 0954406219841650

27. Fuchs D, Schurer S, Tobie T et al (2019) Investigations into nonmetallic inclusion crack area characteristics relevant for tooth root fracture damages of case carburised and shot-peened high strength gears of different sizes made of high-quality steels. Forsch Ingenieurwes. https://doi.org/10.1007/s10010-019-00324-x

28. DIN (Deutsches Institut für Normung e. V.) (2006) Gears-FZG test procedures-Part 1: FZG test method A/8.3/90 for relative scuffing load-carrying capacity of oils (DIN ISO 14635-1)

29. Schurer S, Tobie T, Stahl K (2015) Tragfähigkeitsgewinn im Zahnfuß durch hochreine Stähle [eng.: Load carrying capacity increase in the tooth root due to ultra-clean steels]. FVA, vol 1148 (FVA research project $293 \mathrm{III})$

30. Fuchs D, Tobie T, Stahl K (2021) Untersuchungen zum Fehlstellenversagen an Zahnrädern und deren Einfluss auf die Zahnradtragfähigkeit [eng.: Investigations into the defect failure of gears 
and its influence on the gear load carrying capacity]. FVA, vol 1439. Forschungsvereinigung Antriebstechnik e. V. (FVA), Frankfurt a.M. (FVA research project 293 IV)

31. ISO (International Organization for Standardization) (2016) Calculation of load capacity of spur and helical gears-Part 5: strength and quality of materials (ISO 6336-5)

32. DIN (Deutsches Institut für Normung e. V.) (2019) Heat-treatable steels, alloy steels and free-cutting steels-Part 3: Case-hardening steels (DIN EN ISO 683-3)
33. Alicona Imaging GmbH (2021) InfiniteFocus-Dimensional accuracy \& surface finish measurement. https://www.alicona.com/en/ products/infinitefocus/. Accessed 18 Jan 2021

34. SEP (steel test specification) (2017) Evaluation of inclusions in special steels based on their surface areas-Parts 1 to 3 (SEP 1571) 